\title{
Pyothorax Following Kerosene Ingestion: A Severe Complication of Kerosene Poisoning
}

\author{
Anindya Chattopadhyay ${ }^{1,2}$, Pankaj Halder ${ }^{1,2,3}$, Somak Krishna Biswas ${ }^{2}$, Niladri Mukherjee ${ }^{4}$ \\ ${ }^{1}$ Department of Pediatrics, Medica Superspecialty Hospital, ${ }^{2}$ Department of Pediatrics, Bhagirathi Neotia Woman and Child Care Centre, ${ }^{3}$ Department of Pediatric \\ Surgery, R. G. Kar Medical College, ${ }^{4}$ Department of Pediatric Medicine, Dr. B. C. Roy Post Graduate Institute of Pediatric Sciences, Kolkata, West Bengal, India
}

\section{Abstract}

Pyopneumothorax following kerosene aspiration is not rare in children, but seldom requires surgical intervention. We report a case of kerosene poisoning in a 25-month-old girl where aspiration pneumonitis progressed to pyothorax in spite of supportive medical therapy. Thoracoscopic drainage was done to prevent on-going lung damage and sepsis.

Keywords: Accidental poisoning, empyema thoracis, pneumonitis, steroid, video-assisted thoracoscopy

\section{INTRODUCTION}

Kerosene is a liquid mixture of hydrocarbons which is used for cooking and lighting in developing countries. Unfortunately, it is stored in containers and places which are easily accessible to children. Accidental kerosene poisoning occurs mostly in the age group between 1 and 3 years in developing countries. Pneumonitis due to kerosene initiates an inflammatory reaction independent of bacterial infection. However, serious complications such as atelectasis, lung abscess, empyema, pneumothorax, septicemia, shock, prolonged hospitalization, and death occur rarely. ${ }^{[1]}$ Close monitoring, early diagnosis, and prompt supportive medical therapy (oxygen inhalation, antibiotics, and steroids) are sufficient for successful outcome in majority of aspiration-induced pulmonary complications. This paper reports the first successful treatment of kerosene-induced pyothorax with video-assisted thoracoscopic surgery (VATS) decortication.

\section{Case Report}

A 25-month-old girl was admitted for high fever and vomiting. She had a history of accidental ingestion of kerosene oil 2 days back. Apart from a decreased air entry to the right lung, patchy air space consolidation in the right lower zone of the lung was evident in the chest X-ray on the $5^{\text {th }}$ day. Broad-spectrum intravenous antibiotics and steroid nebulization were

\begin{tabular}{|l|l|}
\hline \multicolumn{2}{|c|}{ Access this article online } \\
\hline Quick Response Code: & Website: \\
& www.ijrc.in \\
& \\
\end{tabular}

started to combat the aspiration pneumonitis. The child responded poorly, and features of moderate pleural effusion on the right side with collapse/consolidation were found in ultrasonography (USG) on the $7^{\text {th }}$ day. Contrast-enhanced computed tomography (CECT) chest showed loculated collection in the right middle and lower lobe with pleural thickening [Figure 1]. As there was loculated empyema with pleural thickening, VATS was planned. Intraoperatively, pus pockets were found around the middle and lower lobe of the right lung, which was cleared followed by breaking of all loculations and decortication of the right lung. Two intercostal chest drains in the second and fifth intercostal spaces (ICS) were placed which were removed on the 3rd and 5 th postoperative day (POD), respectively. The postoperative course was uneventful and included intensive physiotherapy. Satisfactory lung expansion was achieved both clinically and radiologically, and the girl was discharged on the $7^{\text {th }}$ POD. The patient visited in the follow-up clinic after 15 days and was doing well.

Address for correspondence: Dr. Pankaj Halder, Saroda Palli, Sitko Road, Baruipur, Kolkata -700 144, West Bengal, India. E-mail: pankaj.cnmc@gmail.com

This is an open access journal, and articles are distributed under the terms of the Creative Commons Attribution-NonCommercial-ShareAlike 4.0 License, which allows others to remix, tweak, and build upon the work non-commercially, as long as appropriate credit is given and the new creations are licensed under the identical terms.

For reprints contact: WKHLRPMedknow_reprints@wolterskluwer.com

How to cite this article: Chattopadhyay A, Halder P, Biswas SK, Mukherjee N. Pyothorax following kerosene ingestion: A severe complication of kerosene poisoning. Indian J Respir Care 2021;10:120-2.

Received: 08-05-2020 Accepted: $30-08-2020$ Published: 31-01-2021 


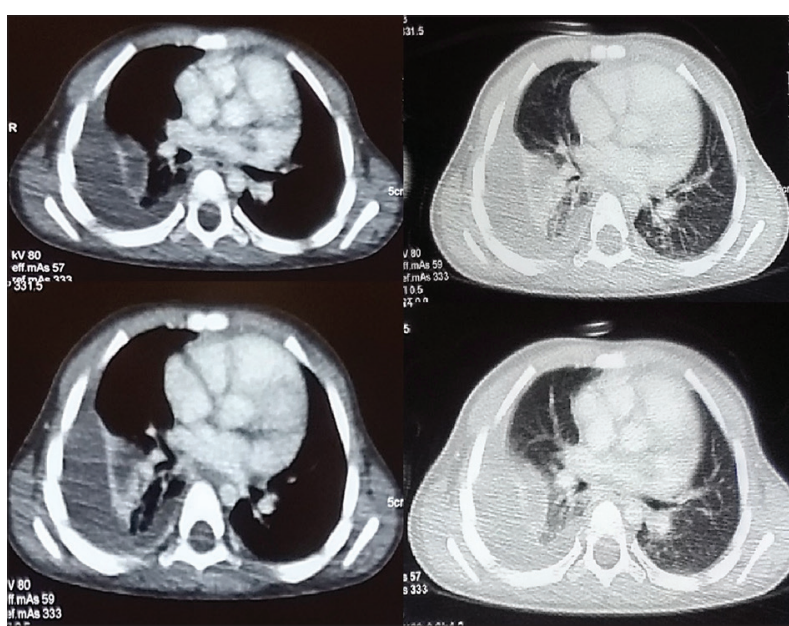

Figure 1: Contrast-enhanced computed tomography thorax in a 2-year 1-month-old girl with kerosene aspiration pneumonitis showing loculated pus collection, pleural thickening, and collapse/consolidation in the lower lobe of the right lung

\section{Discussion}

Accidental kerosene poisoning is still a major concern, during the hot months of the year, in low-and middle-income countries. Abdominal distension and vomiting may be the initial complaints after kerosene ingestion. The morbidity and mortality are primarily related to pulmonary complications and hypoxic encephalopathy. Kerosene is highly volatile, and thus, both inhalation of vapor during ingestion and aspiration due to coughing and vomiting after ingestion are responsible for the lung injury. High mortality was reported by Gupta et al. (4.3\%) and Dudin et al. (2.56\%), while Lucas $(0.57 \%)$ and Ellis et al. $(0.74 \%)$ showed a low fatality rate. ${ }^{[2]}$ The type II pneumocytes are affected mostly resulting in decreased and/or ineffective synthesis of surfactant, interstitial inflammation, intra-alveolar hemorrhage, hyperemia, and bronchial and vascular necrosis. Pneumatoceles can develop in coalescing areas of alveolar and bronchiolar necrosis. Accumulation of lipid material in the alveoli is termed as "lipid pneumonia" which occurs when aspirated kerosene is emulsified and phagocytosed by alveolar macrophages and returned to alveolar space after cell death. It damages the respiratory epithelium, increases the trans-pulmonary pressure, and produces pulmonary interstitial emphysema. Sometimes, this adventitial air enters into the pleural space (pneumothorax) due to rupture of pleural surface. Chronic inflammatory reaction of lung parenchyma, secondary bacterial infections, and hypoxia can worsen the clinical condition and cause life-threatening complications, such as pleural effusion, pyothorax, bronchopleural fistula, and hypoxic encephalopathy ${ }_{.}^{[3,4]}$ Evidence of pulmonary lesion appears in the X-ray and CECT as early as 20 min (even before the onset of clinical symptoms) or as late as $24 \mathrm{~h}$ after the accident. Approximately $71 \%-75 \%$ of symptomatic patients have early radiological evidence of lung lesions such as increased bronchovascular markings and bilateral basal infiltrates. ${ }^{[5]}$
Apart from lung, other organ systems are rarely involved in acute kerosene poisoning because of poor systemic absorption from the gastrointestinal tract. However, kerosene can dissolute the lipids in the stratum corneum and cause varying degree of skin lesions such as bullae, blisters, maculopapular rash, and even first-degree burns. Severe hypoxemia and acidosis may cause depression, ventilatory drive suppression (central nervous system manifestations), and acute renal insufficiency due to type 2 renal tubular acidosis. Cardiac arrhythmias can be manifested due to endogenous catecholamines. Excessive sweating and hypotension may also occur because of autonomic dysfunction. However, polyneuritis, hepatocellular damage, bone marrow suppression, acne, and skin eruptions are seen only in chronic cases. ${ }^{[6,7]}$

Admission, close observation, and clinicoradiological evaluation for at least $8 \mathrm{~h}$ to recognize potential pulmonary complications are utmost important. However, induction of vomiting or gastric lavage is contraindicated due to increased risk of aspiration. For prevention of chemical pneumonitis, steroids (initially at dose of $0.5 \mathrm{mg} / \mathrm{kg}$ and gradually tapered off) along with broad-spectrum antibiotic therapy are recommended. ${ }^{[8]}$ These medications are also helpful in patients who have a preexisting respiratory illness or who develop complications. Bronchoalveolar lavage is reserved for kerosene-induced lipoid pneumonia as it can remove lipid-laden macrophages. ${ }^{[9]}$ We had a rare case of kerosene-induced pyothorax where primary VATS decortication was done as she had loculated collection with pleural thickening. Chaudhary et al. showed intercostal chest tube drainage is not helpful in kerosene-induced pyothorax with septations and pleural thickening with collapse consolidated lung. ${ }^{[10,11]}$

\section{ConcLusion}

Fatal pulmonary complications may arise in accidental kerosene poisoning. Apart from utmost preventive measures to avoid accidental poisoning, all symptomatic patients must be admitted as the prediction of the clinical course of the patient is not possible. Besides, an aggressive approach is required with high index of suspicion for pulmonary complications and low threshold level for early and timely surgical intervention of such cases.

\section{Declaration of patient consent}

We declare that consent has been taken from the patient's father for publishing his daughter's medical condition. He understands that his daughter's names and initials will not be published and due efforts will be made to conceal his daughter's identity.

\section{Financial support and sponsorship \\ Nil.}

\section{Conflicts of interest}

There are no conflicts of interest. 


\section{RefEREnCES}

1. Kumaravel KS, Rameshbabu B. Kerosene poisoning in childhood: A 3-year retrospective study at a tertiary referral hospital. Int J Contemp Med Res 2016;3:1832-4.

2. Kissinger KV, Gowrinath K. Unusual case of accidental kerosene ingestion by an adult. J Clin Sci Res 2015;4:293-5.

3. Franzen D, Kohler M, Degrandi C, Kullak-Ublick GA, Ceschi A. Fire eater's lung: Retrospective analysis of 123 cases reported to a National Poison Center. Respiration 2014;87:98-104.

4. Jin YM, Ge LS, Ji W. Not typical pneumonia: Acute exogenous lipoid pneumonia in 19 children. Int J Clin Exp Med 2016;9:8557-62.

5. Das S, Behera SK, Xavier AS, Selvarajan S. Prophylactic use of steroids and antibiotics in acute hydrocarbon poisoning in children. J Pharm Pract 2020;33:90-5.

6. Patel AL, Shaikh WA, Patel HL, Deshmukh D, Malaviya AP, Janawar P, et al. Kerosene poisoning--Varied systemic manifestations. J Assoc Physicians India 2004;52:65-6.

7. Prasad R, Karmakar S, Sodhi R, Karmakar S. Bilateral hemorrhagic pleural effusion due to kerosene aspiration. Lung India 2011;28:130-2.

8. Ahmadu BU, Chafi AN, Difirwiti HC, Yusuf A, Pwavimbo AJ. An unusual accidental kerosene poisoning. Case Report. ARC J Pediatr 2016;2:1-3.

9. Chen YJ, Hsu CC, Chen KT. Hydrocarbon pneumonitis following fuel siphonage: A case report and literature review. World J Emerg Med 2019;10:69-74.

10. Chaudhary SC, Sawlani KK, Yathish BE, Singh A, Kumar S, Parihar A. Pyopneumothorax following kerosene poisoning. Toxicol Int 2014;21:112-4.

11. Mandal KC, Mandal G, Halder P, Mitra D, Debnath B, Bhattacharya M. Empyema thoracis in children: A 5-year experience in a tertiary care institute. J Indian Assoc Pediatr Surg 2019;24:197-202. 